\title{
Predicting Risk and the Emergence of Schizophrenia
}

\author{
Mary C. Clarke, $P h D^{a, b, *}$, lan Kelleher, $\mathrm{PhD}^{\mathrm{a}}$, \\ Maurice Clancy, MB, MRCPsych ${ }^{\mathrm{a}, \mathrm{c}}$, Mary Cannon, PhD, MRCPsych ${ }^{\mathrm{a}, \mathrm{c}}$
}

\section{KEYWORDS}

- Schizophrenia • Psychiatric risk factors • Environmental risk factors

- Genetic risk factors • Prenatal stress • Obstetric complications • Cannabis

\section{KEY POINTS}

- The presence of certain molecular, biological, and psychosocial factors at certain points in the life span, has been linked to later development of schizophrenia.

- Environmental risk factors for schizophrenia include prenatal exposures, obstetric complications (OCs), childhood trauma, urban birth, migrant status, and adolescent cannabis use.

- Identified risk factors are neither necessary nor sufficient causal factors for schizophrenia. The vast majority of people who are exposed to them do not develop schizophrenia and a majority of individuals with schizophrenia may not have had the specific exposure in question.

- These risk factors cannot be ignored because of their small effect and need to be considered in the context of schizophrenia as a lifelong brain disorder.

\section{INTRODUCTION}

The presence of certain molecular, biologic, and psychosocial factors at certain points in the life span, has been linked to later development of schizophrenia. These include common and rare genetic variants; prenatal exposures, such as infection, stress, and nutrition; OCs; childhood trauma; urban birth; migrant status; and adolescent cannabis use. Some of these risk factors operate on an individual level and some on a societal level but all need to be considered in the context of schizophrenia as a lifelong brain disorder. Research interest in schizophrenia is shifting to ever-earlier stages of the disease process, so the journey to discover the causes of schizophrenia is leading back to late childhood/early adolescence as the important time period in the disease process on which to focus screening and preventative measures.

\footnotetext{
a Department of Psychiatry, Royal College of Surgeons in Ireland, Education and Research Centre, Beaumont Hospital, Dublin 9, Ireland; ${ }^{\text {b }}$ Department of Psychology, Division of Population Health Sciences, Beaux Lane House, Dublin 2, Ireland; ' Department of Psychiatry, Beaumont Hospital, Dublin 9, Ireland

* Corresponding author. Department of Psychiatry, Royal College of Surgeons in Ireland, Education and Research Centre, Beaumont Hospital, Dublin 9, Ireland.

E-mail address: maryclarke@rcsi.ie
} 


\section{OBSTETRIC COMPLICATIONS}

Historical findings show that OCs as a broad category of risk factor for schizophrenia has a modest but consistently found association with schizophrenia. Odds ratios (ORs) of 1.5 to 2.0 have been replicated in several population-based cohort studies using prospective data. ${ }^{1}$ Within this broad category of complications there is good evidence of an association between 10 specific complications and schizophreniathese are complications of pregnancy, such as bleeding, preeclampsia, diabetes, and rhesus incompatibility; abnormal fetal growth and development measures, such as low birth weight, congenital malformations, and small head circumference; and complications of delivery, such as asphyxia, uterine atony, and emergency cesarean section. The evidence supporting an association between these individual complications and schizophrenia comes from the largest studies with the most reliable epidemiologic data that have explored the link between prenatal/neonatal life and the development of schizophrenia in adulthood.

The past decade has seen few comparable studies conducted that have used population-based, prospective data. The only study to do so and to also examine a broad range of OCs was by Byrne and colleagues. ${ }^{2}$ This large, nested, casecontrol study using Danish register-based data found an almost 2-0 fold increase in the rate of schizophrenia among those who had experienced any one of the following complications: maternal nonattendance at antenatal appointments, gestational age of 37 weeks or less, preeclampsia, threatened premature delivery, hemorrhage during delivery, manual extraction of the baby, and maternal sepsis of childbirth and the puerperium. The data was adjusted for the confounding effects of family psychiatric history and socioeconomic and demographic factors. The evidence for the association between OCs and schizophrenia coming from this large, well-controlled study with good quality data is in keeping with previous findings-an association exists but it is modest.

Several other cohort studies using population-based data have recently been conducted but they have only addressed specific OCs, ${ }^{3,4}$ such as the association between fetal growth measures and schizophrenia (in a cohort of Swedish male conscripts); instead of, the association between prenatal exposure to maternal hypertension/diuretic treatment and schizophrenia; and the association between prenatal exposure to analgesics and schizophrenia (both in a Danish cohort using national population-based register data). ${ }^{5,6}$ Finally, one study ${ }^{7}$ examined the association between maternal-fetal blood incompatibility and schizophrenia in a large Californiabased cohort. Evidence from these studies suggests the following:

1. Birth weight is not associated with schizophrenia when gestational age is taken into account.

2. Maternal hypertension and diuretic treatment during pregnancy are OCs of noteexperience of either one in the third trimester independently increases the odds of the exposed offspring developing schizophrenia 2-fold and experience of both increases the odds 4 -fold.

3. Prenatal exposure to analgesics is an $\mathrm{OC}$ equally worthy of note with exposure increasing the odds of schizophrenia 4-fold, after adjustment for the confounding effects of parental history of schizophrenia, prenatal infection exposure, exposure to other drugs in the prenatal period, other pregnancy complications, and parental social status and parental age.

4. Maternal-fetal blood incompatibility leads to a 2-fold increase in the rate of schizophrenia in adulthood among exposed offspring. 
It is possible that OCs have a direct effect on fetal neurodevelopment ${ }^{8}$-for example, evidence suggests that perinatal hypoxia may have lasting effects on dopaminergic function. The same data also suggest, however, a further indirect effect of OCs such that birth insults alter the manner in which dopamine function is regulated by stress in adulthood. ${ }^{9}$ Cannon and colleagues ${ }^{10}$ have recently found that neurotrophic factors, perhaps stimulated in response to fetal distress, may be important in the origin of schizophrenia. In this nested case-control study, assays from cord and maternal blood samples taken at delivery showed that, among schizophrenia patients, birth hypoxia was associated with a $20 \%$ decrease in brain-derived neurotrophic factor (BDNF) whereas among the matched healthy controls birth hypoxia was associated with a $10 \%$ increase in BDNF. The deleterious effects of OCs, such as hypoxia and hyperbilirubinaemia, on $N$-methyl-D-aspartate (NMDA) receptors have also been proposed as a potential mechanism. ${ }^{11}$

Hypoxia itself has been proposed to mediate the effects of other OCs. Cannon and colleagues $^{12}$ found a linear relationship between the number of hypoxia causing OCs, such as abnormal fetal heart rate, third-trimester heart rate, placental hemorrhaging, and risk of schizophrenia, suggesting that any association between these specific OCs and schizophrenia is accounted for by the effect of hypoxia on risk for schizophrenia. These data also suggest that hypoxia interacts with genetic susceptibility to further increase risk. The risk of schizophrenia increased with the number of hypoxia-related OCs within families-given genetic vulnerability to schizophrenia, those who were exposed to hypoxia were more likely to develop schizophrenia than family members not exposed to hypoxia.

\section{CANNABIS USE}

Over the past 5 years, robust epidemiologic studies with prospective data on cannabis use have shown that cannabis confers an increase in risk for schizophrenia. Several reviews and meta-analyses examining this association have been published since 2004 and all have concluded that the evidence supports cannabis as a component cause of schizophrenia. ${ }^{13}$ The results of the meta-analyses varied from an overall 2-fold to a 2.9-fold increase in later schizophrenia outcomes in cannabis users. Early-onset or adolescent-onset cannabis use confers an even higher risk of later schizophrenia-approximately 4-fold.

The majority $(90 \%)$ of adolescents who abuse cannabis do not develop schizophrenia. The risk for psychotic illness attached to cannabis use seems influenced by the amount used and the duration of use as well as the type or strength of cannabis. ${ }^{14}$ Individual genetic susceptibility may also be important. Caspi and colleagues, ${ }^{15}$ using data from the Dunedin Multidisciplinary Health and Development Study, showed that individuals with the high-activity allele (val) of the COMT gene were more likely to develop schizophrenia or schizophreniform disorder in adulthood if they had used cannabis in adolescence, with the effect more marked in those who had used cannabis earlier in adolescence, whereas this effect was not seen among individuals who were homozygous for the low-activity (Met) allele. Individuals who were heterozygous ( $\mathrm{Val} / \mathrm{Met}$ ) were also found at increased risk, but the effect was less marked. Both self-report and informant reports of psychotic symptoms yielded a similar pattern of results, ${ }^{16}$ with findings that cannabis use is associated with a greater frequency of hallucinogenic experiences in Val allele carriers who had high psychosis liability at baseline. It is not yet known how cannabis exerts its effect on risk of psychosis, but it seems likely to involve changes in dopamine transmission. 
On balance, the evidence suggests that cannabis may only exert a modest increase in relative risk on an individual level but has a much greater effect at a population level given its widespread use in the general population. It has been estimated that $8 \%$ to $15 \%$ of all schizophrenia can be attributed to cannabis use. $^{17,18}$

\section{PRENATAL INFECTION}

Mednick and colleagues ${ }^{19}$ first reported an increased risk of schizophrenia among individuals exposed prenatally to the 1957 influenza epidemic in Helsinki. Most subsequent studies examining this issue have found a positive association but there have also been some negative findings (Brown ${ }^{20}$ provides an extensive review of this literature). One reason for the inconsistent results is likely to be the differing methodologies used across studies, with earlier studies using ecologic designs in which large populations were deemed exposed if they were in utero at the time of an influenza epidemic and later studies taking advantage of archived maternal serum to establish individual exposure to the infection. Earlier studies pointed to the importance of exposure to infection during the second trimester of fetal development, but the more robust recent work places the window of vulnerability in the first trimester. ${ }^{21,22} \mathrm{~A}$ wide variety of infections, such as influenza, herpes, polio, rubella, toxoplasmosis, and respiratory infections, have been implicated. The effect sizes reported for the association between prenatal exposure to infection and later schizophrenia have generally been in the region of a 1.5-fold to 2 -fold increase in risk. ${ }^{23,24}$ Studies using prenatal serum samples, however, have found that those exposed prenatally to rubella had a 10-20fold increase in risk of adult schizophrenia ${ }^{25}$ and that those exposed during the first trimester of gestation to influenza had a 7 -fold increase in risk. ${ }^{22}$ There is some evidence that prenatal exposure to infection may be interacting with another risk factor for schizophrenia, such as genetic risk, to produce its effect. ${ }^{26}$ We found an additive effect of having a positive family history such that, when coupled with prenatal exposure to infection, the risk is significantly increased relative to either risk factor on its own. There was an almost 5-fold increase in the odds of having schizophrenia for individuals with both psychosis liability and prenatal infection exposure compared with individuals without either risk factor.

Despite much speculation, the mechanism by which prenatal infection increases the risk of schizophrenia has not yet been elucidated. An indirect effect of infection on fetal brain development seems the most plausible pathogenic mechanism. The wide range of infections associated with schizophrenia during the prenatal period indicates that some pathogenic mechanism common to many infections, such as the maternal immune response to infection, may be in operation. Possible indirect mechanisms include maternal IgG antibodies elicited by the infection or an infection-induced excess of maternal cytokines, either of which may damage the developing fetus. ${ }^{27}$ A positive association between elevated maternal levels of the cytokine interleukin-8 during pregnancy and an increased risk of schizophrenia spectrum disorders in the offspring has been found. 22

The findings of immune dysregulation in schizophrenia ${ }^{28}$ and evidence of abnormal expression of immune-related genes in postmortem schizophrenia studies ${ }^{29}$ support the idea of the maternal immune response as the important mechanism. Animal models of infection have provided evidence that the maternal immune response affects fetal brain development in ways that are consistent with neuropathology seen in schizophrenia. Abnormalities in the hippocampus and cortex as well as in cerebellar white matter and evidence of altered behavior, such as deficits in social 
interaction and prepulse inhibition of the startle response, have been found in animal models of maternal infection. ${ }^{30}$ In addition, there is evidence that some of the behavioral deficits are ameliorated by administration of antipsychotic medication ${ }^{30}$ and that several other risk factors for schizophrenia, such as winter birth, urban birth, fetal hypoxia, maternal stress, and maternal nutrition, elevate cytokine levels. ${ }^{30}$ This finding suggests that perhaps maternal immune response may mediate the effects of other environmental risk factors that have been assumed to have independent effects on risk of schizophrenia.

\section{PRENATAL STRESS}

There is a growing body of literature examining the causal relationship between prenatal exposure to stress and the development of schizophrenia and other psychotic disorders in adulthood. The prenatal stress/schizophrenia association has been examined in several different ways. Death of spouse ${ }^{31,32}$ and experience of catastrophic events, such as war ${ }^{33}$ and nuclear explosion, ${ }^{34}$ have been found to increase the risk of schizophrenia among those exposed. van Os and Selten ${ }^{33}$ found an increased relative risk (RR) of schizophrenia (RR 1.28) among those in the Netherlands who were in their first or second trimester during the Nazi invasion in May 1940, and Malaspina and colleagues ${ }^{35}$ found that those in their second month of gestation during the 1967 Arab-Israel War (Six-Day War) also had an increased risk of schizophrenia. Imamura and colleagues ${ }^{34}$ found that those exposed in their second or third trimester to the nuclear explosion in Nagasaki were at increased risk of schizophrenia. Myhrman and colleagues ${ }^{36}$ showed that the risk of schizophrenia among unwanted children was raised compared with wanted or mistimed children, even after adjustment for confounding by sociodemographic, pregnancy, and perinatal variables (odds ratio [OR] 2.4). This study examined self-ratings of a woman's desire to be pregnant. The ratings were gathered prospectively beginning in the sixth or seventh month of gestation. The association was present after accounting for both maternal depression and measures of fetal well-being at the time of the birth. Khashan and colleagues ${ }^{32}$ found that death or serious illness of a relative during the first trimester was associated with an increased risk of developing schizophrenia, even when several potential confounders were controlled for. This partially replicates the classic finding of Huttunen and Niskanen. ${ }^{31}$ This study showed that those whose fathers had died during their fetal period were at an increased risk of schizophrenia compared with those whose fathers had died during early childhood. This epidemiological evidence has been supported by recent animal work linking prenatal stress and impaired behavioral adjustment/ emotional reactivity in the offspring.

As in the infection studies, the diversity of stress exposures associated with schizophrenia raises the possibility of a single pathophysiologic mechanism underlying the association. The common denominator could be the stress response and the resulting glucocorticoid hormones known to be precipitated by psychological stressors. ${ }^{37}$ Animal models of prenatal stress have informed our understanding of the mechanisms at play. For example, it has been shown in humans that the greatest sensitivity of the developing fetus to stress is likely to be during late first or second trimester of pregnancy, ${ }^{19}$ when, based on animal evidence, glucocorticoid receptor expression is commencing in the developing fetal brain. The precise timing of glucocorticoid receptor expression in the developing human brain, however, is currently unknown. Collectively, the findings from animal studies suggest that exposure of the developing brain to stress-induced glucocorticoid hormones generates a syndrome that recreates some aspects of the schizophrenia phenotype. ${ }^{38}$ 
The majority of studies, however, that have examined the prenatal stress/schizophrenia association have not had information on maternal adverse responses to stress, such as substance abuse, which may mediate the association. And there is evidence that the schizophrenia-risk-increasing effect of maternal stress during pregnancy may overlap with the risk-inducing effects of other environmental factors, thus making it hard to delineate independent effects of some of the risk factors discussed in this article. For example, psychological stress and neuroendocrine markers of stress can affect immune function and, therefore, susceptibility to infection ${ }^{39}$; maternal stress during pregnancy has been shown to increase the risk of fetal hypoxia, ${ }^{40}$ which, in turn, has been show to increase the risk of schizophrenia; and stress has been shown to alter people's eating behavior, steering them toward sweet and fatty foods ${ }^{41}$ and possibly leading to maternal micronutritional deficiencies during pregnancy.

\section{CHILDHOOD TRAUMA}

Recent evidence has shown that childhood trauma is a risk factor for the development of schizophrenia ${ }^{42-44}$ and psychotic symptoms. ${ }^{45}$ Although several previous studies have suffered from methodological limitations, such as small, highly selected samples and nonstandardized measures of trauma, a recent study has sought to overcome these problems. Heins and colleagues ${ }^{46}$ examined exposure to childhood trauma among nonaffective psychosis patients from geographically representative clinics in Holland and Belgium. Siblings of patients and healthy control were recruited as comparison groups. The use of a sibling comparison group helped to control for any unmeasured familial confounding in the associations examined. Heins and colleagues showed that those with childhood trauma had 4 times the odds of developing a psychotic disorder and that there was a dose-response effect present such that patients had more trauma exposure than their siblings, who, in turn, had more trauma exposure than the healthy comparison group. In addition, childhood abuse, but not neglect, was significantly associated with the positive symptoms of psychosis; there was no such association with negative symptoms. This finding indicates that there may be symptom-specific and exposure-specific mechanisms at play.

Our work has shown significant associations between psychotic symptoms in early adolescence and reports of child physical abuse, exposure to domestic violence, and involvement in bullying ${ }^{45}$ and that cannabis use and childhood trauma both independently increased the risk for psychotic symptoms in adolescence. ${ }^{44}$ Both cannabis use and childhood trauma, however, additively interacted to increase the likelihood of psychotic symptoms in adolescence to a much greater extent than either risk factor independently. This indication of environmental factors working together to produce a synergistic effect on risk has been found in other studies. Cougnard and colleagues $^{47}$ examined data from 2 large European population cohort studies (1 adult cohort and 1 cohort aged 14-24 years) and calculated the additive interaction between 3 environmental risk factors for psychosis (cannabis use, childhood trauma, and urbanicity) and baseline psychotic experiences in predicting persistence of psychotic experiences. The authors concluded that level of environmental risk combines synergistically with subclinical psychotic symptoms to cause abnormal persistence of these symptoms.

\section{PRENATAL NUTRITION}

Evidence for the involvement of prenatal nutrition in the pathway to schizophrenia in some individuals has come from several sources. First, ecological evidence comes from the study of populations exposed to famine. Individuals exposed to the Dutch 
Hunger Winter (1944-1945) and individuals exposed to the Great Chinese Famine (1958-1961) had a greater risk of developing schizophrenia compared with those not exposed to these famines. Although data of this ecological nature are open to methodologic criticisms, data from studies on micronutritional deficiencies and risk of schizophrenia come from more robust studies. There is evidence that deficiencies of folate, vitamin D, iron, and protein during the prenatal period all independently increase the risk of schizophrenia. Homocysteine levels are linked to folate in the metabolic cycle ${ }^{48}$; and elevated maternal homocysteine levels in the third trimester have been shown to be associated with a 2-fold increase in risk of schizophrenia in the offspring. McGrath and colleagues ${ }^{49-51}$ have shown that vitamin D supplementation in males in Finland reduced the incidence among these individuals and that both low and high concentrations of neonatal vitamin $D$ are associated with an increase risk of schizophrenia; and a large Danish showed that those exposed to prenatal iron deficiency had a 4-fold increase in risk of schizophrenia. There has been some evidence to suggest that polyunsaturated fatty acids deficiency during gestation increases the risk of schizophrenia but this evidence has largely been indirect and from animal studies. McGrath and colleagues have also shown that vitamin D-deficient rats have features characteristic of schizophrenia, such as enlarged ventricles, a thinner neocortex, and altered behavior in adulthood, such as hyperlocomotion and impaired latent inhibition. ${ }^{52}$ There is also animal evidence suggesting that exposure to suboptimal levels of protein in utero leads to abnormalities in brain development that are similar to those seen in schizophrenia patients, such as a reduced number of hippocampal cells, and affects behavior in ways consistent with the schizophrenia phenotype, such as reduced prepulse inhibition and adverse effects on learning and memory. ${ }^{53}$

Several biological pathways, both direct and indirect, possibly mediate the association between prenatal nutritional deficiency and later schizophrenia. Direct effects are possible because many micronutrients are important components of molecules in neurodevelopment and indirect effects are possible because it is plausible that nutritional deficiencies could result in de novo mutations in genes critical for brain development. ${ }^{54}$ Table 1 outlines some of the recent studies examining environmental risk factors for schizophrenia.

\section{EPILEPSY AS A RISK FACTOR FOR SCHIZOPHRENIA}

The nature of the relationship between psychosis and epilepsy has been of great interest to psychiatrists for more than a century. ${ }^{62-65}$ The majority of studies ${ }^{66-68}$ have found a higher prevalence of psychosis in patients with epilepsy compared with the general population, but this finding varies greatly, with reported rates varying from $0.48 \%{ }^{69}$ to $35.7 \% .{ }^{70} \mathrm{~A}$ seminal Icelandic population study surveyed a complete population of all individuals with epilepsy in Iceland and reported a rate of psychosis of $7.2 \% .^{71}$

In a systematic review and meta-analysis that we conducted, the pooled prevalence rate for schizophrenia in epilepsy patients was $1.3 \%(95 \% \mathrm{Cl}, 0.7-1.7)$ (Fig. 1). This percentage was found after pooling a total of 17 articles. A large Danish populationbased study found that people with a history of epilepsy have nearly 2.5 times the risk of developing schizophrenia and nearly 3 times the risk of developing a schizophrenia-like psychosis compared with the general population. ${ }^{72}$ It was also found that both a family history of psychosis and a family history of epilepsy increase the risk of schizophrenia.

In a population-based family study examining shared susceptibility to epilepsy and psychosis, we found that individuals with epilepsy had a 5.5-fold increase in the odds 


\begin{tabular}{|c|c|c|}
\hline Risk Factor & Author & Description \\
\hline \multicolumn{3}{|l|}{ 1. Obstetric complications } \\
\hline Medication & $\begin{array}{l}\text { Sørensen et al, }{ }^{6} 2004 \\
\text { Sørensen et al, }{ }^{5} 2003\end{array}$ & $\begin{array}{l}\text { Danish cohort study: OR } 4.7(95 \% \mathrm{Cl}, 1.9-12.0) \text { for prenatal exposure to analgesics in the } \\
\text { second trimester } \\
\text { Danish cohort study: OR } 4.0(95 \% \mathrm{Cl}, 1.4-11.4) \text { for prenatal exposure to both hypertension } \\
\text { and diuretic treatment in the third trimester }\end{array}$ \\
\hline Rhesus incompatibility & $\begin{array}{l}\text { Hollister et al, }{ }^{55} 1996 \\
\text { Insel et al, }{ }^{7} 2005\end{array}$ & $\begin{array}{l}\text { Case-control study: rate of } 2.1 \% \text { vs } 0.8 \% \text { for Rh incompatible vs Rh compatible } \\
\text { Californian cohort study: RR } 2.2(95 \% \mathrm{Cl}, 1.1-4.4) \text { for male offspring where there was } \\
\text { maternal-fetal blood incompatibility }\end{array}$ \\
\hline 2. Cannabis use & $\begin{array}{l}\text { Henquet et al, }{ }^{17} 2005 \\
\text { Moore et al, }{ }^{18} 2007\end{array}$ & $\begin{array}{l}\text { Meta-analysis of epidemiological studies with prospective data: pooled OR } 2.1(95 \% \mathrm{Cl}, 1.7-2.5) \\
\text { Meta-analysis of epidemiological studies with prospective data: pooled OR } 1.4(95 \% \mathrm{Cl}, 1.2-1.6)\end{array}$ \\
\hline \multicolumn{3}{|l|}{ 3. Prenatal infection } \\
\hline
\end{tabular}


4. Prenatal stress

\begin{tabular}{|c|c|c|}
\hline Death/illness of relative & $\begin{array}{l}\text { Huttunen and } \\
\quad \text { Niskanen, }{ }^{31} 1978 \\
\text { Khashan et al, }{ }^{32} 2008\end{array}$ & $\begin{array}{l}\text { Finnish cohort study: significant increase in risk for prenatal compared with postnatal death } \\
\text { of spouse } \\
\text { Danish birth cohort: RR } 1.67(95 \% \mathrm{Cl}, 1.0-2.7) \text { for death of relative during first trimester }\end{array}$ \\
\hline War & $\begin{array}{l}\text { van Os and Selten, } 1998^{33} \\
\text { Malaspina et al, }{ }^{35} 2008\end{array}$ & $\begin{array}{l}\text { Dutch birth cohort: RR } 1.1(95 \% \mathrm{Cl}, 1.0-1.2) \text { for exposure in second trimester } \\
\text { Jerusalem birth cohort: hazard ratio } 2.3(95 \% \mathrm{Cl}, 1.1-4.7) \text { for first-trimester exposure }\end{array}$ \\
\hline Unwanted pregnancy & Myhrman et al, ${ }^{36} 1996$ & Finnish birth cohort: OR $2.5(95 \% \mathrm{Cl}, 1.5-4.2)$ for children of unwanted pregnancies \\
\hline 5. Childhood trauma & $\begin{array}{l}\text { Kelleher et } \mathrm{al}^{45} 2008 \\
\text { Harley et } \mathrm{al}^{44} 2010 \\
\text { Heins et al, }{ }^{46} 2011\end{array}$ & $\begin{array}{l}\text { Irish cohort study: OR } 5.9(95 \% \mathrm{Cl}, 1.2-27.9) \text { for childhood physical abuse and risk of psychotic } \\
\text { symptoms in adolescence } \\
\text { Irish cohort study: OR } 6.1(95 \% \mathrm{Cl}, 1.6-23.1) \text { for childhood trauma and psychotic symptoms } \\
\text { Case-control study: OR } 4.5(95 \% \mathrm{Cl}, 2.7-7.3) \text { for childhood trauma and nonaffective psychotic } \\
\text { disorder }\end{array}$ \\
\hline \multicolumn{3}{|l|}{ 6. Prenatal nutrition } \\
\hline Iron deficiency & $\begin{array}{l}\text { Insel et al, }{ }^{51} 2008 \\
\text { Sørensen et al, }{ }^{60} 2010\end{array}$ & $\begin{array}{l}\text { Californian cohort study: RR } 3.7(95 \% \mathrm{Cl}, 1.4-9.8) \text { for maternal mean hemoglobin of } \\
10 \mathrm{~g} / \mathrm{dL} \text { or less } \\
\text { Danish cohort study: OR } 1.6(95 \% \mathrm{Cl}, 1.2-2.2) \text { for maternal anemia during pregnancy }\end{array}$ \\
\hline Homocysteine & Brown et al, ${ }^{48} 2007$ & $\begin{array}{l}\text { Nested case-control study: OR } 2.3(95 \% \mathrm{Cl}, 1.1-4.8) \text { for elevated third-trimester } \\
\text { homocysteine levels }\end{array}$ \\
\hline
\end{tabular}




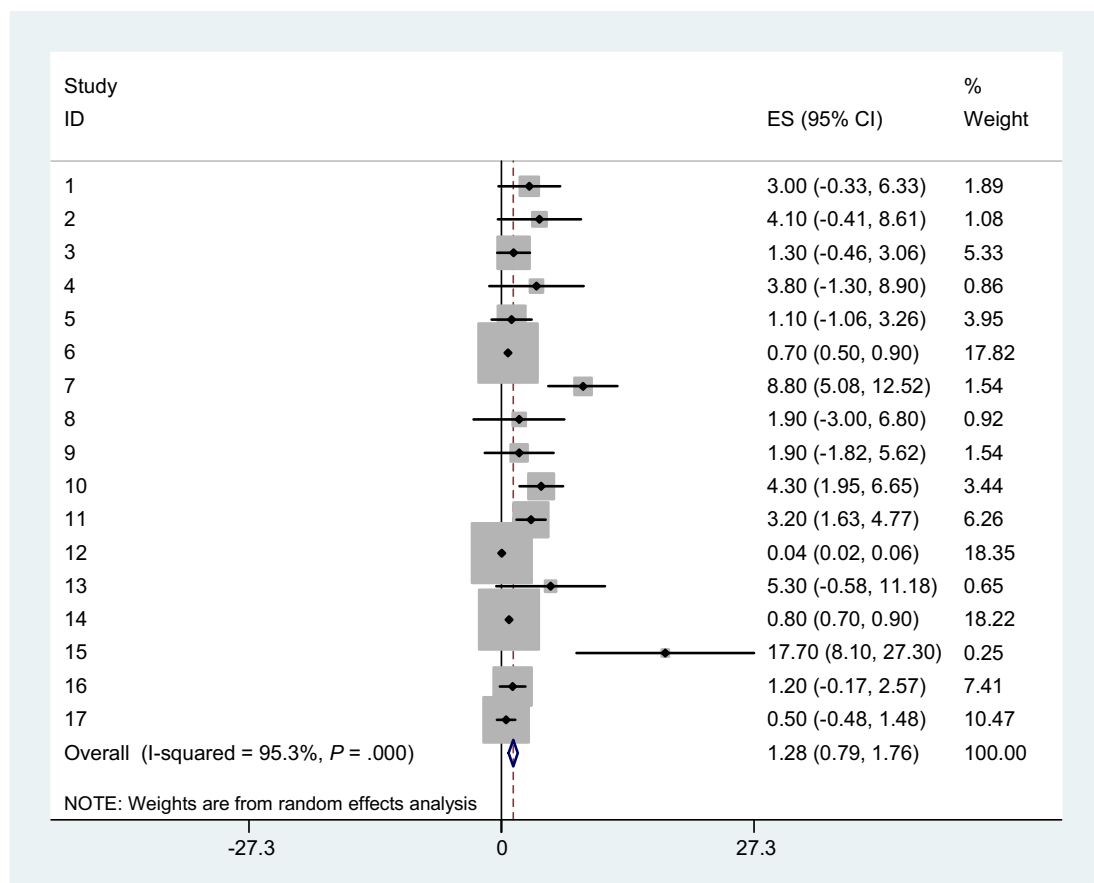

Fig. 1. Prevalence of schizophrenia in epilepsy (1.3\%).

of having a broadly defined psychotic disorder and an almost 8.5-fold increase in the odds of having schizophrenia. ${ }^{73}$ There was strong evidence of clustering of the association between epilepsy and psychosis within families. Individuals with a parental history of epilepsy had a 2-fold increase in the odds of developing a psychotic disorder compared with patients without a parental history of epilepsy. Reciprocally, individuals with a parental history of psychotic disorder had a 2.8-fold increase in the odds of having a diagnosis of generalized epilepsy compared with individuals without a parental history of psychosis.

This evidence suggests that epilepsy and psychotic illness may represent different outcomes of a common etiologic process. Neuropathologic, neuroimaging, and genetics findings show that similar structural brain abnormalities and genetic abnormalities are present in patients with schizophrenia and patients with epilepsy. ${ }^{74-77}$ For instance, enlarged ventricles have been found common to first-episode psychosis and temporal lobe epilepsy patients without psychosis. ${ }^{78}$ Neuronal migration defects have been proposed as a mechanism related to enlarged ventricles and this defect could be common to schizophrenia and epilepsy. From a neurobiological perspective, significant gray matter and white matter deficits occur in temporal lobe epilepsy with psychosis. Some of these deficits overlap with those found in schizophrenia. These include the medial temporal structures but also extend to lateral temporal and extratemporal regions. ${ }^{79}$ Recent genetic work shows that a rare genetic mutation can lead to either epilepsy or schizophrenia. A microdeletion in the genomic area 15q13-14 containing the nicotine receptor was linked to development of either schizophrenia or juvenile epilepsy. ${ }^{77}$

In summary, a history of epilepsy in patients increases their risk of developing schizophrenia. An improved understanding of the mechanism underlying this 
association would be a fruitful line of inquiry and may yield useful information on the etiopathogenesis of both psychosis and epilepsy.

\section{ACQUIRED BRAIN INJURY AS A RISK FACTOR FOR SCHIZOPHRENIA}

Acquired brain injury $(\mathrm{ABI})$ increases the risk of psychiatric illness ${ }^{80-82}$ but the question of whether $\mathrm{ABI}$ is a risk factor for schizophrenia remains controversial. Earlier studies stated that there was a 2 -fold to 3-fold increased risk of psychosis after an $\mathrm{ABI} .{ }^{83}$ More recent studies have contradicted this view and reported that there is limited evidence between an association between head injury and psychosis. ${ }^{83-85}$ Consensus is divided and this can often lead to difficulties from a medicolegal viewpoint.

We conducted a recent systematic review and meta-analysis on population-based controlled studies and showed a significant association between traumatic brain injury and schizophrenia with an OR of 1.65 (95\% Cl, 1.17-2.32). It is difficult, however, to definitively establish causality. Patients who develop psychosis after head injury may already have been at risk of psychosis before the injury. Confounders include illicit substance use. In patients with a family history of psychosis, the contribution of head injury may be greater to susceptible patients. Two family studies yielded a pooled OR of $2.8(95 \% \mathrm{Cl}, 1.17-2.32)$. The impact of head injuries seems to be greater among those with an inherited susceptibility to schizophrenia. ${ }^{86,87}$ Studies have also found an increased rate of pre-existing psychosis among people with head injury and it is thought that psychosis increases the risk for $\mathrm{ABI}{ }^{88}$ The apparent complexity of the causal pathway between $A B I$ and schizophrenia adds to the difficulty of investigating this relationship. Influences of gene-environment interaction or an epigenenetic mechanism must be considered.

There does not seem to be a dose-response between the severity of the head injury and the subsequent risk of schizophrenia. When subdivided by severity of $A B I$, the pooled ORs were similar in studies providing rates for mild head injury specifically (1.17) to estimates for severe head injury (1.18). Achte and colleagues ${ }^{89}$ followed-up 3552 Finnish soldiers who had received head injuries during World War II. During this period, $2.6 \%$ developed psychoses resembling schizophrenia, which is much higher than the incidence expected in the normal population. Soldiers with mild head injuries developed schizophrenia more frequently than those with severe head injuries. Factors independent of the injury may play a decisive role.

\section{ANTI-NMDA RECEPTOR ENCEPHALITIS AS A RISK FACTOR FOR SCHIZOPHRENIA}

Anti-NMDA receptor encephalitis is a severe form of encephalitis associated with antibodies against NR1 and NR2 subunits and occurs primarily in females. Prominent features on initial presentation include psychotic symptoms and may be misdiagnosed as first-onset schizophrenia. ${ }^{90}$ There can be motor changes, such as catatonia, seizures, and dyskinesias. There are also behavioral changes, autonomic dysfunction, and impaired consciousness. ${ }^{91}$ The combination of psychotic symptoms with catatonia and orofacial dyskinesias, which are indicators of dopaminergic involvement, are all consistent with the effects of the NMDA receptor antagonist, phencyclidine, which replicates many aspects of the presentation of schizophrenia. ${ }^{92}$ It is also implicated in phencyclidine induced psychosis.

The psychiatric presentations of these cases of anti-NMDA receptor encephalitis thus provide important support for the NMDA receptor hypofunction hypothesis for psychosis and the possibility that autoantibodies to the NMDA receptor subunits may be implicated in the development of psychosis is novel. 


\section{GENETICS OF SCHIZOPHRENIA Family Studies}

Historically, the evidence from family studies of schizophrenia have shown that that a sibling or child of a person with schizophrenia has a 10-fold increased risk of developing schizophrenia compared with the risk in the general population. ${ }^{93}$ The risk in a recent large register-based study has shown lower risks (ORs 2-4) and lack of specificity for schizophrenia among offspring of parents with nonaffective psychosis. ${ }^{94}$ Adoption and cross-fostering studies show an increased risk of schizophrenia in the biological but not the adoptive families of schizophrenic adoptees. ${ }^{95}$

\section{Twin Studies and the Heritability Index}

Twin studies have shown that the concordance rates for schizophrenia in monozygotic (MZ) twins is approximately $40 \%$ to $50 \%$ whereas the concordance rate for dizygotic (DZ) twins is $6 \%$ to $10 \% .^{96,97}$ Heritability estimates are approximately $80 \%$, which make schizophrenia among the most heritable of psychiatric disorders. Heritability calculations assume, however, no interactions among genes or between gene and the environment -an assumption that may have significant implications for the validity of these estimations. ${ }^{98}$ Another assumption is that $\mathrm{MZ}$ twins share their environment to an equal degree as DZ twins. This assumption may not be valid in particular when considering the prenatal environment because $M Z$ pairs differ from $D Z$ pairs in terms of sharing the placenta (ie, $M Z$ twins are more likely to share a placenta). For this reason, $M Z$ twins may share more of the prenatal environment than $D Z$ twins and, as discussed in this article, prenatal life is a rich source of risk factors for later schizophrenia. The risk of schizophrenia and schizophrenia-related disorders is similar for the offspring of both affected and unaffected $M Z$ twins, ${ }^{99,100}$ providing support for the presence of unexpressed genotypes in schizophrenia and the importance of epigenetics.

\section{Genome-Wide Association Studies}

Over the past 2 decades there has been a concentration of effort and resources in investigating the molecular genetics of schizophrenia (for review, see the article by Gejman and colleagues ${ }^{101}$ ). The initial approach involved candidate gene studies and more than 1000 genes have been studied in schizophrenia (www.szgene.org) but with little replication of findings. The newer approach has been to use genomewide association studies (GWAS), which interrogate the genome systematically and are independent of a prior hypothesis (Table 2). To date, 12 GWAS studies have been published, but, despite large sample sizes, the problem of nonreplication has not been eliminated. The largest study, a mega-analysis with a discovery sample of 21,856 and a replication of samples of 29,839 individuals, was published in October 2011 by the Schizophrenia Psychiatric Genome-Wide Association Study Consortium and found 5 new schizophrenia loci not previously identified in the other GWAS. ${ }^{102}$ The best-replicated finding from GWAS is evidence for involvement of the major histocompatibility complex (MHC) locus. The $\mathrm{MHC}$ locus has a high gene density but genes with an immune function predominate-which links back to the epidemiologic data on infections and autoimmunity as risk factors for schizophrenia (discussed elsewhere). Another notable feature of these GWAS studies is the small effect sizes of the genes identified. ORs are usually approximately 1.10. An elegant analysis by the International Schizophrenia Consortium ${ }^{103}$ estimated that hundreds (perhaps thousands) of genes may be involved in conferring risk for schizophrenia, each with small effect. The investigators showed that an aggregate score, derived from the 


\begin{tabular}{|c|c|c|c|}
\hline Authors and Year & Sample (Case-Control) & Gene or Region & OR \\
\hline Lencz et $\mathrm{al}{ }^{159} 2007$ & $178 / 144$ & CSF2RA, SHOX & 3.23 \\
\hline Sullivan et al, ${ }^{160} 2008$ & 738/733 & AGBL1 & 6.01 \\
\hline O'Donovan et al, ${ }^{161} 2008$ & $\begin{array}{l}\text { Discovery: 479/2937 } \\
\text { Follow-up: } 6829 / 9987 \\
\end{array}$ & ZNF804A & 1.12 \\
\hline Need et al, ${ }^{162} 2009$ & $\begin{array}{l}\text { Discovery: } 871 / 863 \\
\text { Follow-up: } 1460 / 12,995\end{array}$ & ADAMTSL3 & 0.68 \\
\hline Purcell et al, ${ }^{163} 2009$ (ISC) & $3322 / 3587$ & $\mathrm{MHC}$ & 0.82 \\
\hline $\begin{array}{l}\text { Stefansson et al, }{ }^{164} \\
2009 \text { (SGENE) }\end{array}$ & $\begin{array}{l}\text { Discovery: } 2663 / 13,498 \\
\text { Follow-up: } 4999 / 15,555\end{array}$ & $\begin{array}{l}\text { MHC } \\
\text { NRGN } \\
\text { TCF4 } \\
\end{array}$ & $\begin{array}{l}1.16 \\
1.15 \\
1.23 \\
\end{array}$ \\
\hline Shi et al, ${ }^{165} 2009$ (MGS) & $\begin{array}{l}2681 / 2653 \\
1286 / 973 \text { (AA) }\end{array}$ & $\begin{array}{l}\text { MHC } \\
\text { CENTG2 } \\
\text { ERBB4 } \\
\end{array}$ & $\begin{array}{l}0.88 \\
1.23 \\
0.73 \\
\end{array}$ \\
\hline Ikeda et al, ${ }^{166} 2010$ & $575 / 564$ & OAT & 0.57 \\
\hline Yue et al, ${ }^{167} 2011$ & $\begin{array}{l}\text { Discovery: 746/1599 (AA) } \\
\text { Follow-up: 4027/5603 (AA) }\end{array}$ & $\begin{array}{l}\text { ZKSCAN4 } \\
\text { NKAPL } \\
\text { PGBD1 } \\
\text { TSPAN18 } \\
\end{array}$ & $\begin{array}{l}0.79 \\
0.78 \\
0.79 \\
1.29 \\
\end{array}$ \\
\hline Shi et al, ${ }^{168} 2011$ & $\begin{array}{l}\text { Discovery: } 3750 / 6468 \text { (AA) } \\
\text { Follow-up: } 4383 / 4539 \text { (AA) }\end{array}$ & $\begin{array}{l}\text { Rs10489202 } \\
\text { Rs1060041 } \\
\text { Rs11586522 } \\
\text { Rs16887244 } \\
\text { Rs1488935 } \\
\end{array}$ & $\begin{array}{l}1.12 \\
1.11 \\
1.04 \\
0.83 \\
0.871 \\
\end{array}$ \\
\hline Gejman et al, ${ }^{101} 2011$ (PGC) & $\begin{array}{l}\text { Discovery: } 9394 / 12,462 \\
\text { Follow-up: } 8442 / 21,397\end{array}$ & $\begin{array}{l}\text { MIR137 } \\
\text { PCGEM1 } \\
\text { TRIM26 } \\
\text { CSMD1 } \\
\text { MMP16 } \\
\text { CNNM2 } \\
\text { NT5C2 } \\
\text { STT3A } \\
\text { CCDC68 } \\
\text { TCF4 }\end{array}$ & $\begin{array}{l}1.12 \\
1.20 \\
1.15 \\
1.11 \\
1.10 \\
1.10 \\
1.15 \\
1.11 \\
1.10 \\
1.23\end{array}$ \\
\hline
\end{tabular}

Abbreviations: AA, Asian ancestry; ISC, International schizophrenia consortium; MGS, molecular genetics of schizophrenia study; PGC, schizophrenia psychiatric genome-wide association study consortium; SGENE, A large scale genome-wide association study of schizophrenia addressing variation in expressivity and contribution from environmental factors.

top $10 \%$ to $50 \%$ of a set of 74,000 single-nucleotide polymorphisms (SNPs) from the association results in a discovery sample, can predict up to $3 \%$ of the variance in a target group. Using a different approach, Agerbo and colleagues ${ }^{104}$ came to the same conclusion and reported that the percentage of excess risk associated with a family history of schizophrenia mediated through genome-wide SNP variation ranged up to a maximum of $4 \%$. This raises the question, "Where is the missing heritability?"105,106 It may be surmised that the "missing heritability" is likely to lie in the environment or gene-environment interaction, which is not captured by individual SNPs or their combination. The area of epigenetics is a promising area of investigation in the coming years. 


\section{Copy Number Variation Studies}

In addition to the reports of common SNP variations, many rare structural genomic variants, such as copy number variants (CNVs), have been identified (for review, see the article by Gejman and colleagues $\left.{ }^{101}\right)$. These rare variants seem to have larger effect sizes than SNPs but many are private mutations confined to single families. These variants are not specific to schizophrenia and confer risk for a variety of conditions, such as epilepsy, autistic spectrum disorder, and attention-deficit/hyperactivity disorder. An interesting aspect of these structural variants is that so many affect genes are implicated in brain development, which links nicely with the neurodevelopmental hypothesis of schizophrenia described first in the late 1980s and discussed elsewhere in this article. Apart from their rarity, a problematic aspect of the large CNVs identified to date is that they span multiple genes and the contribution of each gene may be difficult to disentangle. Nevertheless, some commentators hold that these rare variants could hold the key to explaining the transmission of schizophrenia and argue that mutations with the largest effects in individuals, regardless of their frequency in the population, is the most informative as to the underlying pathogenesis of schizophrenia.

Several conclusions can be drawn from the GWAS and CNV studies so far:

- Common variants for schizophrenia identified to date are of small effect.

- There is substantial overlap between the genetic architecture of schizophrenia and bipolar disorder.

- There is a large unexplained gap between heritability estimates from family studies and the amount of genetic variation that can be attributed to genomewide SNP variation.

\section{GENE-ENVIRONMENT INTRERACTION}

There are strong indications, from several sources, that gene/environment interactions are important in the cause of schizophrenia. There is evidence from animal work that neuregulin-1 and DISC1 may modify the consequences of prenatal immune activation $^{107,108}$ and that neuregulin 1 may modify the effect of exposure to social defeat. ${ }^{107}$ There is also evidence from human studies that COMT may modify the effects of adolescent exposure to cannabis, ${ }^{15}$ that individuals at high genetic risk for schizophrenia are particularly sensitive to the adverse effects of a negative family rearing environment, ${ }^{109}$ and the effect of urbanicity is mediated by genetic liability to psychosis. ${ }^{110}$ The urbanicity studies found that $60 \%$ to $70 \%$ of those in the sample who developed schizophrenia did so as a result of the synergistic action between urban dwelling and familial liability to psychosis.

Our study of prenatal infection and family history of psychosis found that up to half of the cases of schizophrenia in the sample could be attributed to the synergistic action of prenatal infection exposure and familial liability to psychotic disorder. The possibility of OCs interacting with underlying genetic vulnerability has been raised by several other lines of evidence. ${ }^{111-114}$ In particular, recent findings show that many of the susceptibility genes identified for schizophrenia are affected by hypoxia. ${ }^{115-117}$ Nicodemus and colleagues ${ }^{116}$ performed a gene-environment interaction analysis in a family study of schizophrenia probands, siblings, and controls. The authors examined whether a set of schizophrenia candidate genes affected by hypoxia or involved in vascular function in the brain interacted with serious OCs to influence risk for schizophrenia. They found that 4 of the 13 genes examined showed evidence for significant serious OC-by-gene interaction. All of the OCs rated as 
serious had the potential to cause hypoxia-the most common were bleeding during pregnancy, extended labor, delivery problems, and respiratory distress at birth. The 4 genes found to interact with these OCs, AKT 1 , BDNF, GRM3, and DTNBP 1 , showed previous evidence of an association with schizophrenia and were affected by hypoxia. In keeping with the epidemiological findings discussed previously, the OCs identified in this study were diverse and occurred during both prenatal and perinatal periods. The overall evidence suggests that these exogenous environmental factors are working on a developmentally vulnerable brain in which endogenous factors have gone awry to produce synergistic increases in risk of schizophrenia in adulthood.

\section{PREVENTION}

If gene-environment interaction is important in the etiology of schizophrenia, then preventing the environmental exposures will reduce some of the risk associated with susceptibility genes as well as reducing the risk associated with the independent effects of the environmental exposures. It has been calculated that there is an infection population-attributable proportion of $30 \%$ in the samples used to analyze the associations between schizophrenia and influenza, toxoplasmosis, and genital-reproductive infections. If these 3 infections had been prevented, then there would have been $30 \%$ fewer cases of schizophrenia in the patient groups examined in these studies. It has also been suggested that the start of influenza immunization may have been responsible for a reduction in the rate of schizophrenia beginning in the 1950 s. ${ }^{118}$ Evidence like this has been used in support of suggestions that greater coverage of the pregnant population with wide-ranging immunization would decrease the incidence of schizophrenia in the general population. McGrath and colleagues ${ }^{50}$ have calculated that almost $44 \%$ of the schizophrenia cases in a Danish cohort may have been due to nonoptimal neonatal vitamin D levels. McGrath and colleagues ${ }^{49}$ had previously presented evidence that vitamin D supplementation in males in Finland was associated with a reduction in the incidence of schizophrenia in that population, indicating the potential usefulness of supplementation at a population level for micronutritional deficiencies. As noted by McGrath and Lawlor, ${ }^{119}$ however, although infection and nutrition may be the exposures most amenable to public health intervention, the evidence is not yet robust enough to justify such action.

Fig. 2 shows the multifactorial, highly complex potential causal pathways to schizophrenia. It seems likely that some seemingly independent risk factors are actually taking place at different times along the same causal pathway. If the antecedent factors can be identified, perhaps through large cohorts with multiples exposures measured, then where best to aim preventative strategies can be investigated. For example, as discussed previously, there is evidence that maternal stress during pregnancy increases the risk of fetal hypoxia. If maternal stress during pregnancy can be prevented or reduced, then some of the risk associated with hypoxia may be able to be reduced.

\section{CLINICAL PREDICTION OF PSYCHOSIS RISK: THE ULTRA-HIGH-RISK APPROACH}

Psychosis is usually preceded by a prodromal period before full-blown illness. This period is characterized by the presence of psychotic symptoms at a subthreshold level of intensity and/or duration or frequency compared with established psychotic disorder. Although the psychosis prodrome is, by definition, a retrospective diagnosis, several research groups have developed criteria aimed at prospectively identifying young people during the prodrome, before onset of first-episode psychosis. These criteria have been formalized in several instruments, including the Comprehensive 


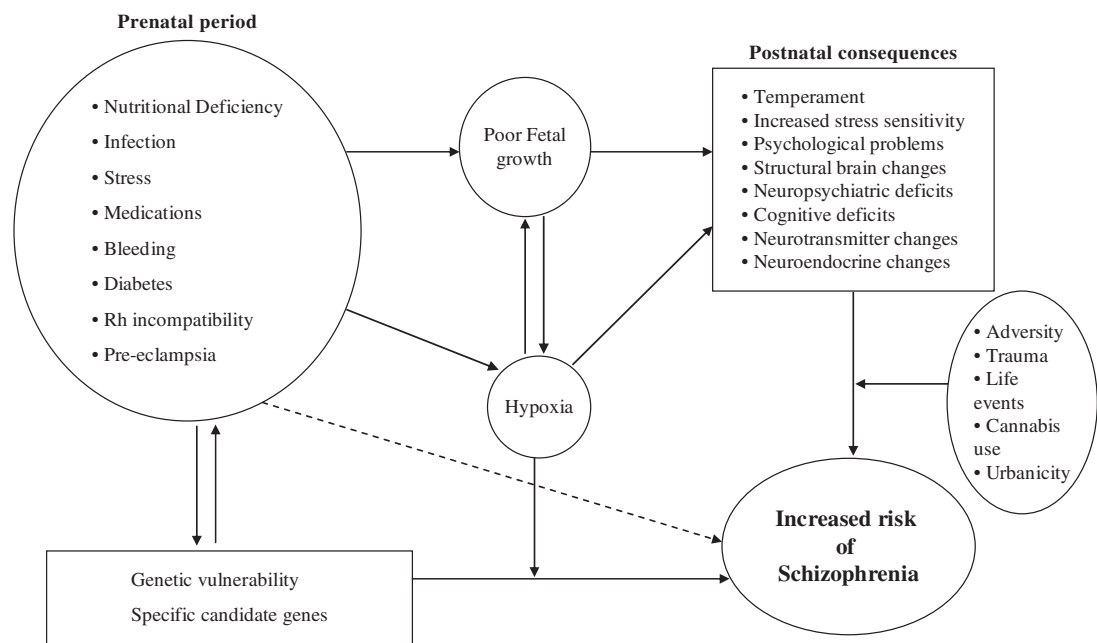

Fig. 2. Proposed pathways and mechanisms linking OCs and risk of schizophrenia. (Reproduced from Clarke MC, Roddy S, Cannon M. Obstetric complications and schizophrenia: historical overview and new directions. In: Brown AS, Patterson PH, editors. The origins of schizophrenia. New York: Columbia University Press; 2011. p. 96-119; with permission.)

Assessment of At-Risk Mental States ${ }^{120}$ and the Structured Interview for Prodromal Syndromes. ${ }^{121}$ Three prodromal risk syndromes have been described in these instruments, characterized by

1. Attenuated positive symptoms

2. Frank psychotic symptoms that are brief in duration or

3. Genetic risk combined with functional deterioration

Prospective studies have demonstrated that approximately $15 \%$ to $40 \%$ of young people who present to the clinic with these putative prodromal risk syndromes go on to develop a psychotic disorder within the proceeding 2 years. ${ }^{122-126}$ As a result, these individuals are considered an ultra-high-risk (UHR) group for psychosis. ${ }^{127}$

\section{Neurocognitive Manifestations of Psychosis Risk}

A great deal of research has been conducted addressing neurocognitive risk factors associated with prodromal risk syndromes, which helps inform about the underlying pathophysiology associated with psychosis risk. This has included research on working memory, attention/vigilance, executive functioning, verbal learning/memory, and speed of processing. Research has shown impairments across most of these cognitive domains in UHR samples.

\section{Working memory}

Verbal and spatial working memory have both been shown to be impaired in UHR samples, using assessments, such as letter-number span tasks, delayed matchto-sample tasks, spatial board tasks, and hidden tokens tasks. Several different groups have demonstrated verbal and spatial working memory deficits in UHR samples. ${ }^{128-133}$ Wood and colleagues, ${ }^{134}$ for example, demonstrated spatial working memory deficits in an Australian sample of 38 UHR patients using a block-tapping test. Smith and colleagues $^{135}$ have also shown spatial working memory deficits in an American sample 
of 8 UHR patients. Hawkins and colleagues ${ }^{136}$ demonstrated verbal working memory deficits on a letter-number sequencing task in a sample of 36 Canadian and American UHR patients, a finding recently replicated by Carrion and colleagues ${ }^{137}$ in a larger sample of UHR patients $(n=127)$ also using the letter-number sequencing task.

\section{Attention and vigilance}

The Continuous Performance Test is the classic task used in neurocognitive assessments of attention and vigilance. Hambrecht and colleagues ${ }^{138}$ conducted one of the earliest such tests in a sample of 51 putatively prodromal patients and found that the UHR sample demonstrated significantly poorer scores compared with healthy controls. Attention deficits have now been demonstrated many times across different studies. ${ }^{131-134}$

\section{Executive function}

Tasks, such as the Wisconsin Card Sorting Test (WCST) and the Tower of Hanoi, are among the most commonly used measures of executive functioning in UHR samples. Several groups have demonstrated executive function deficits in UHR patients. ${ }^{130-132}$ Pukrop and colleagues ${ }^{139}$ showed deficits on the WCST in a German sample of 90 UHR patients. Pflueger and colleagues, ${ }^{129}$ using both the WCST and Tower of Hanoi tasks, also found executive functioning deficits in a sample of 60 UHR patients in Basel, Switzerland. Most recently, in one of the largest studies to date, Carrion and colleagues $^{137}$ showed deficits on the WCST in a sample of 127 UHR patients.

\section{Verbal learning/memory}

Several different tasks are used to assess verbal learning and memory, which include assessing the participants' ability to immediately recall words as well as their ability to recall the words after a delay. The California Verbal Learning Test, Hopkins Verbal Learning Test, and the Rey Auditory Verbal Learning Test are frequently used, with immediate and delayed testing trials, as well as the Wechsler Memory Scale. Verbal learning tasks regularly show some of the greatest levels of impairment relative to other neurocognitive domains. ${ }^{137-142}$ Niendam and colleagues, ${ }^{142}$ for example, showed pronounced verbal learning deficits in a sample of 4512 -year-old to 29year-old UHR patients attending a prodromal clinic in California. Similarly, Jhashan and colleagues ${ }^{143,144}$ demonstrated marked deficits in verbal learning in a sample of 48 12-year-old to 30 -year-old patients with prodromal syndromes.

\section{Processing speed}

Tests of processing speed have been used less frequently than tests of other neurocognitive domains but have consistently demonstrated, in studies incorporating them, some of the most marked neurocognitive impairments. Processing speed tasks used have included the Trail Making Test, digit symbol-coding test, the Stroop Color and Word Test, and verbal fluency tests. ${ }^{130}$ Hawkins and colleagues ${ }^{136}$ found deficits in a sample of 36 American and Canadian UHR patients using a digit symbol-coding task and the Stroop Color and Word Test. Eastvold and colleagues ${ }^{130}$ reported that a sample of 40 UHR patients performed significantly more poorly on the Stroop Color and Word Test compared with healthy controls. Simon and colleagues ${ }^{140}$ reported poorer scores in a sample of 69 UHR patients on both the Trail Making Test and verbal fluency tests. Frommann and colleagues ${ }^{132}$ found, in a sample of German patients who were in the early versus late stages of the prodrome, that although patients in the later stage of the prodrome demonstrated a range of neurocognitive deficits, early-stage prodromal patients uniquely showed processing speed deficits. The authors have recently conducted one of the first studies of prodromal syndromes 
outside the clinic setting. ${ }^{145}$ Among a population sample of 11-year-old to 13-year-old patients, up to $8 \%$ fulfilled criteria for a prodromal risk syndrome. Using the Measurement and Treatment Research to Improve Cognition in Schizophrenia (MATRICS) consensus neurocognitive battery, young people who met criteria for prodromal risk syndromes demonstrated deficits in processing speed, including on the Trail Making Test, Part A, and the symbol-coding task from the Brief Assessment of Cognition in Schizophrenia, as well as deficits in nonverbal working memory, using the Wechsler Memory Scale spatial span task. ${ }^{146}$ Deficits were most pronounced on the symbolcoding task from the Brief Assessment of Cognition in Schizophrenia ( $z$ score difference between UHR group and controls $=1$ ), in line with the findings of Frommann and colleagues ${ }^{132}$ that processing speed deficits are the main finding in the early UHR stages.

In the largest study to date of neurocognitive functioning in patients with prodromal syndromes, Seidman and colleagues ${ }^{133}$ found that processing speed, measured with a symbol-coding task, was the most pronounced of all neurocognitive deficits. Most recently, Carrion and colleagues ${ }^{137}$ have also shown in a large sample of American UHR patients that not only were processing speed deficits especially pronounced relative to most other neurocognitive deficits but also processing speed deficits were uniquely predictive of social and role functioning, independent of positive psychotic symptoms. This is interesting given that some researchers have suggested that symbol-coding deficits reflect the core of schizophrenia neurocognitive impairment. ${ }^{147,148}$ In a meta-analysis of 40 studies, Dickinson ${ }^{148}$ reported that the effect size of the impairment on a symbol-coding task significantly exceeded the effect sizes of tasks commonly used to measure more specific cognitive domains, including episodic memory, executive function, and working memory. This, they have argued, represents a systems-based dysfunction, which may be at the heart of psychosis risk, reflecting a process of disturbed integration and coordination between distributed brain networks.

\section{The Community Approach}

Although UHR research has been in progress in the clinic, a parallel stream of research has been ongoing in the general population, studying psychosis from a broader perspective, that is, individuals in the community who experience isolated psychotic symptoms. These symptoms are especially prevalent in young people, with metaanalyses demonstrating a median population prevalence of $17 \%$ among children ages 9 years to 12 years and $7.5 \%$ among adolescents ages 13 years to 18 years. ${ }^{149}$ By comparison, a meta-analysis of (mainly) adult studies demonstrated a population prevalence of $5 \%$ for psychotic symptoms. ${ }^{150}$ The presence of these symptoms at a subclinical level in the community is of clinical interest because, as in UHR studies, longitudinal research has demonstrated that these symptoms are associated with increased risk for psychotic disorder in adulthood, albeit not to the same degree as in UHR patients. In an influential article, Poulton and colleagues ${ }^{151}$ demonstrated that community-based children who reported psychotic symptoms at age 11 were, at age 26, at a 5-fold to 16-fold increased risk of schizophreniform disorder. This finding was replicated by researchers in an Australian sample, who showed that self-reported auditory hallucinations at age 14 years were associated with increased risk for psychotic disorder at age $21 .{ }^{152}$ Young people in the general population who report psychotic symptoms have been shown to share a wide range of risk factors with schizophrenia patients, including social, environmental, substance use, obstetric, developmental, anatomic, and intellectual risk factors. ${ }^{153}$ For these reasons, this population has been considered to form part of an extended psychosis phenotype, 
comprised of ostensibly healthy community-based individuals with occasional psychotic symptoms on one end and schizophrenia patients on the other end. Researchers have argued that work on this extended psychosis phenotype may provide valuable insights into the etiology of clinical psychotic disorder. ${ }^{154,155}$ Neurocognitive research has only recently begun on this population but some of the cognitive differences that are characteristic of the prodrome and first-episode psychosis have already been shown to also occur in this population. In particular, deficits in processing speed have been found pronounced in this group. Blanchard and colleagues, ${ }^{156}$ for example, showed that, in addition to poorer scores in tests of receptive language and motor skills, young people with psychotic symptoms performed more poorly on the Trail Making Test, Part B. This is in line with a previous cohort study, which demonstrated that childhood performance on this task predicted schizophrenia in adulthood. ${ }^{157}$ Using the MATRICS battery in a sample of more than 200 communitybased adolescents, we have recently shown that psychotic symptoms are associated with significantly poorer scores in tests of processing speed and working memory, with performance on digit symbol-coding particularly pronounced. ${ }^{158}$ This mirrors findings in UHR sample as well as in first-episode psychosis.

\section{SUMMARY}

There is strong evidence for involvement of a range of environmental risk factors in the pathway to schizophrenia. These include OCs, prenatal infection, prenatal stress, prenatal nutrition, and adolescent cannabis use. These risk factors, however, are neither necessary nor sufficient causal factors for schizophrenia. The majority of people who are exposed to them do not develop schizophrenia and a majority of individuals with schizophrenia may not have had the specific exposure in question. These risk factors are component causes embedded in highly complex pathways to schizophrenia in which some of these risk factors may add to, mediate, or moderate each other's effects. Just as with genetic risk factors, however, a risk factor should not be ignored because it is of small effect. It is likely that these environmental risk factors also affect the outcome of genetic risk factors for schizophrenia through gene/environment interaction and/or through epigenetic effects. In addition, work studying the etiologic overlap between neurodevelopmental disorders, such as epilepsy and schizophrenia, and work on the extended psychosis phenotype are starting to provide potentially valuable insights into the etiology of clinical psychotic disorder.

\section{REFERENCES}

1. Cannon M, Jones PB, Murray RM. Obstetric complications and schizophrenia: historical and meta-analytic review. Am J Psychiatry 2002;159:1080-92.

2. Byrne M, Agerbo E, Bennedsen B, et al. Obstetric conditions and risk of first admission with schizophrenia: a Danish national register based study. Schizophr Res 2007;97:51-9.

3. Gunnell D, Rasmussen F, Fouskakis D, et al. Patterns of fetal and childhood growth and the development of psychosis in young males: a cohort study. Am J Epidemiol 2003;158:291-300.

4. Gunnell D, Harrison G, Whitley E, et al. The association of fetal and childhood growth with risk of schizophrenia. Cohort study of 720,000 Swedish men and women. Schizophr Res 2005;79:315-22.

5. Sørensen HJ, Mortensen EL, Reinisch JM, et al. Do hypertension and diuretic treatment in pregnancy increase the risk of schizophrenia in offspring? Am J Psychiatry 2003;160:464-8. 
6. Sørensen HJ, Mortensen EL, Reinisch JM, et al. Association between prenatal exposure to analgesics and risk of schizophrenia. Br J Psychiatry 2004;160: 366-71.

7. Insel BJ, Brown AS, Bresnahan MA, et al. Maternal-fetal blood incompatibility and the risk of schizophrenia in offspring. Schizophr Res 2005;80:331-42.

8. Boog G. Obstetrical complications and further schizophrenia of the infant: a new methodological threat to the obstetrician? J Gynecol Obstet Biol Reprod 2003; 32:720-7.

9. Boksa P, El-Khodor BF. Birth insult interacts with stress at adulthood to alter dopaminergic function in animal models: possible implications for schizophrenia and other disorders. Neurosci Biobehav Rev 2003;27:91-101.

10. Cannon TD, Yolken R, Buka S, et al. Collaborative study group on the perinatal origins of severe psychiatric D. Decreased neurotrophic response to birth hypoxia in the etiology of schizophrenia. Biol Psychiatry 2008;64:797-802.

11. Dalman C. Obstetric complications and risk of schizophrenia: an association appears undisputed, yet mechanisms are still unknown. Lakartidningen 2003; 100:1974-9.

12. Cannon TD, Rosso IM, Hollister JM, et al. A prospective cohort study of Genetic and perinatal influences in the etiology of schizophrenia. Schizophr Bull 2000; 26:249-56.

13. Casadio P, Di Forti M, Murray RM. Cannabis use as a component cause of schizophrenia. In: Brown AS, Patterson PH, editors. The origins of schizophrenia. Columbia University Press; 2011. p. 157-75.

14. Di Forti M, Morgan C, Dazzan P, et al. High-potency cannabis and the risk of psychosis. Br J Psychiatry 2009;195(6):488-91.

15. Caspi A, Moffitt TE, Cannon M, et al. Moderation of the effect of adolescentonset cannabis use on adult psychosis by a functional polymorphism in the catechol-O-methyltransferase gene: longitudinal evidence of a gene $X$ environment interaction. Biol Psychiatry 2005;57(10):1117-27.

16. Henquet C, Rosa A, Delespaul P, et al. COMT ValMet moderation of cannabisinduced psychosis: a momentary assessment study of 'switching on' hallucinations in the flow of daily life. New York: Columbia University Press; Acta Psychiatr Scand 2009;119(2):156-60.

17. Henquet C, Murray R, Linszen D, et al. The environment and schizophrenia: the role of cannabis use. Schizophr Bull 2005;31(3):608-12.

18. Moore TH, Zammit S, Lingford-Hughes A, et al. Cannabis use and risk of psychotic or affective mental health outcomes: a systematic review. Lancet 2007;370(9584):319-28.

19. Mednick SA, Machon RA, Huttunen MO, et al. Adult schizophrenia following prenatal exposure to an influenza epidemic. Arch Gen Psychiatry 1988;45: 189-92.

20. Brown AS. Maternal infection and schizophrenia. In: Brown AS, Patterson PH, editors. The origins of schizophrenia. New York: Columbia University Press; 2011. p. 25-57.

21. Brown AS, Cohen P, Greenwald $S$, et al. Nonaffective psychosis after prenatal exposure to rubella. Am J Psychiatry 2000;157:438-43.

22. Brown AS, Begg MD, Gravenstein S, et al. Serologic evidence of prenatal influenza in the etiology of schizophrenia. Arch Gen Psychiatry 2004;61: 774-80.

23. Cannon M, Kendell R, Susser E, et al. Prenatal and perinatal risk factors for schizophrenia. In: Murray RM, Jones PB, Susser E, et al, editors. The 
epidemiology of schizophrenia. Cambridge (UK): Cambridge University Press Cambridge University Press; 2002. p. 74-99.

24. Clarke MC, Harley M, Cannon M. The role of obstetric events in schizophrenia. Schizophr Bull 2006;32:3-8.

25. Brown AS, Cohen P, Harkavy-Friedman J, et al. Prenatal rubella, premorbid abnormalities, and adult schizophrenia. Biol Psychiatry 2001;49(6):473-86.

26. Clarke MC, Tanskanen A, Huttunen M, et al. Evidence for an Interaction between familial liability and prenatal exposure to infection in the causation of schizophrenia. Am J Psychiatry 2009;166(9):1025-30.

27. Gilmore JH, Jarskog LF. Exposure to infection and brain development: cytokines in the pathogenesis of schizophrenia. Schizophr Res 1997;24(3): 365-7.

28. Sperner-Unterweger B. Immunological aetiology of major psychiatric disorders: evidence and therapeutic implications. Drugs 2005;65(11):1493-520.

29. Arion D, Unger T, Lewis DA, et al. Molecular evidence for increased expression of genes related to immune and chaperone function in the prefrontal cortex in schizophrenia. Biol Psychiatry 2007;62(7):711-21.

30. Patterson PH. Anmial models of the maternal infection risk factor. In: Brown AS, Patterson PH, editors. The origins of schizophrenia. Columbia University Press; 2011. p. 255-81.

31. Huttunen MO, Niskanen P. Prenatal loss of father and psychiatric disorders. Arch Gen Psychiatry 1978;35(4):429-31.

32. Khashan AS, Abel KM, McNamee R, et al. Higher risk of offspring schizophrenia following antenatal maternal exposure to severe adverse life events. Arch Gen Psychiatry 2008;65(2):146-52.

33. van Os J, Selten JP. Prenatal exposure to maternal stress and subsequent schizophrenia. The May 1940 invasion of The Netherlands. $\mathrm{Br} J$ Psychiatry 1998;172:324-6.

34. Imamura $Y$, Nakane $Y$, Ohta $Y$, et al. Lifetime prevalence of schizophrenia among individuals prenatally exposed to atomic bomb radiation in Nagasaki City. Acta Psychiatr Scand 1999;100(5):344-9.

35. Malaspina D, Corcoran C, Kleinhaus KR, et al. Acute maternal stress in pregnancy and schizophrenia in offspring: a cohort prospective study. BMC Psychiatry 2008;8:71.

36. Myhrman A, Rantakallio P, Isohanni M, et al. Unwantedness of a pregnancy and schizophrenia in the child. Br J Psychiatry 1996;169(5):637-71.

37. Koenig JI, Kirkpatrick B, Lee P. Glucocorticoid hormones and early brain development in schizophrenia. Neuropsychopharmacology 2002;27(2): 309-18.

38. Patterson PH. Anmial models of the maternal stress risk factor. In: Brown AS, Patterson PH, editors. The origins of schizophrenia. New York: Columbia University Press; 2011. p. 335-64.

39. Iampietro MC, Ellman LM. Maternal stress during pregnancy and schizophrenia. In: Brown AS, Patterson PH, editors. The origins of schizophrenia. Columbia University Press; 2011. p. 120-39.

40. Sharma S, Norris WE, Kalkunte S. Beyond the threshold: an etiological bridge between hypoxia and immunity in preeclampsia. J Reprod Immunol 2010; 85(1):112-6.

41. Epel E, Lapidus R, McEwen B, et al. Stress may add bite to appetite in women: a laboratory study of stress-induced cortisol and eating behavior. Psychoneuroendocrinology 2001;26(1):37-49. 
42. Read J, van Os J, Morrison AP, et al. Childhood trauma, psychosis and schizophrenia: a literature review with theoretical and clinical implications. Acta Psychiatr Scand 2005;112:330-50.

43. Morgan C, Fisher $H$. Environmental factors in schizophrenia: childhood trauma-a critical review. Schizophr Bull 2007;33:3-10.

44. Harley M, Kelleher I, Clarke M, et al. Cannabis use and childhood trauma interact additively to increase the risk of psychotic symptoms in adolescence. Psychol Med 2010;40(10):1627-34.

45. Kelleher I, Harley M, Lynch F, et al. Associations between childhood trauma, bullying and psychotic symptoms among a school-based adolescent sample. Br J Psychiatry 2008;193:378-82.

46. Heins M, Simons C, Lataster T, et al. Childhood trauma and psychosis: a casecontrol and case-sibling comparison across different levels of genetic liability, psychopathology, and type of trauma. Am J Psychiatry 2011;168(12):1286-94.

47. Cougnard A, Marcelis M, Myin-Germeys I, et al. Does normal developmental expression of psychosis combine with environmental risk to cause persistence of psychosis? A psychosis proneness-persistence model. Psychol Med 2007; 37:513-27.

48. Brown AS, Bottiglieri T, Schaefer CA, et al. Elevated prenatal homocysteine levels as a risk factor for schizophrenia. Arch Gen Psychiatry 2007;64(1):31-9.

49. McGrath J, Saari K, Hakko H, et al. Vitamin D supplementation during the first year of life and risk of schizophrenia: a Finnish birth cohort study. Schizophr Res 2004;67(2-3):237-45.

50. McGrath JJ, Eyles DW, Pedersen CB, et al. Neonatal vitamin D status and risk of schizophrenia: a population-based case-control study. Arch Gen Psychiatry 2010;67(9):889-94.

51. Insel BJ, Schaefer CA, McKeague IW, et al. Maternal iron deficiency and the risk of schizophrenia in offspring. Arch Gen Psychiatry 2008;65(10):1136-44.

52. Cui X, Eyles DW, Burne TH, et al. Developmental Vitamin D deficiency as a risk factor for schizophrenia. In: Brown AS, Patterson PH, editors. The origins of schizophrenia. New York: Columbia University Press; 2011. p. 282-99.

53. Tarantino LM, Reyes TM, Palmer AA. Animal models of prenatal protein malnutrition relevant for schizophrenia. In: Brown AS, Patterson $\mathrm{PH}$, editors. The origins of schizophrenia. Columbia University Press; 2011. p. 300-34.

54. Harper KN, Brown AS. Prenatal nutrition and the etiology of schizophrenia. In: Brown AS, Patterson PH, editors. The origins of schizophrenia. New York: Columbia University Press; 2011. p. 58-95.

55. Hollister JM, Laing P, Mednick SA. Rhesus incompatibility as a risk factor for schizophrenia in male adults. Arch Gen Psychiatry 1996;53:19-24.

56. Brown AS, Schaefer CA, Quesenberry CP Jr, et al. Maternal exposure to toxoplasmosis and risk of schizophrenia in adult offspring. Am J Psychiatry 2005; 162(4):767-73.

57. Brown AS, Schaefer CA, Quesenberry CP Jr, et al. No evidence of relation between maternal exposure to herpes simplex virus type 2 and risk of schizophrenia? Am J Psychiatry 2006;163(12):2178-80.

58. Brown AS, Schaefer CA, Wyatt RJ, et al. Maternal exposure to respiratory infections and adult schizophrenia spectrum disorders: a prospective birth cohort study. Schizophr Bull 2000;26(2):287-95.

59. Babulas V, Factor-Litvak P, Goetz R, et al. Prenatal exposure to maternal genital and reproductive infections and adult schizophrenia. Am J Psychiatry 2006; 163(5):927-9. 
60. Sørensen HJ, Nielsen PR, Pedersen CB, et al. Association between prepartum maternal iron deficiency and offspring risk of schizophrenia: population-based cohort study with linkage of Danish national registers. Schizophr Bull 2011; 37(5):982-7.

61. McGrath J, Eyles D, Mowry B, et al. Low maternal vitamin D as a risk factor for schizophrenia: a pilot study using banked sera. Schizophr Res 2003;63(1-2):73-8.

62. Esquirol E. Des maladies mentales considerees sous les rapports medical. JB Balliere; 1838.

63. Kraeplin E. Psychiatrie: Ein Lehrbuch fur Studierende und Artze. Leipzig (Germany): Barth; 1913.

64. Flor-Henry P. Psychosis and temporal lobe epilepsy. A controlled investigation. Epilepsia 1969;10(3):363-95.

65. Trimble MR. The psychoses of epilepsy. New York: Raven Press; 1991.

66. Gibbs EL, Gibbs FA, Fuster B. Psychomotor epilepsy. Arch Neurol Psychiatry 1948;60(4):331-9.

67. Slater E, Beard AW, Glithero E. The schizophrenialike psychoses of epilepsy. Br J Psychiatry 1963;109:95-150.

68. Schmitz B. Psychosis in epilepsy: frequency and risk factors. J Epilepsy 1995;8: 295-305.

69. Swinkels WA, Kuyk J, van Dyck R, et al. Psychiatric comorbidity in epilepsy. Epilepsy Behav 2005;7(1):37-50.

70. Jensen I, Larsen JK. Mental aspects of temporal lobe epilepsy. Follow-up of 74 patients after resection of a temporal lobe. J Neurol Neurosurg Psychiatry 1979; 42(3):256-65.

71. Gudmundsson G. Epilepsy in Iceland. A clinical and epidemiological investigation. Acta Neurol Scand 1966;43(Suppl 25):1-124.

72. Qin P, Xu H, Laursen TM, et al. Risk for schizophrenia and schizophrenia-like psychosis among patients with epilepsy: population based cohort study. BMJ 2005;331(7507):23.

73. Clarke M, Tanskanen A, Huttunen MO, et al. Evidence for shared genetic susceptibility to epilepsy and psychosis: a population based family study. Biol Psychiatry 2012;71(9):836-9.

74. Bruton CJ, Stevens JR, Frith CD. Epilepsy, psychosis, and schizophrenia: clinical and neuropathologic correlations. Neurology 1994;44(1):34-42.

75. Helbig I, Mefford HC, Sharp AJ, et al. 15q13.3 Microdeletions increase risk of idiopathic generalized epilepsy. Nat Genet 2009;41(2):160-2.

76. Masurel-Paulet A, Andrieux J, Callier P, et al. Delineation of 15q13.3 microdeletions. Clin Genet 2010;78(2):149-61.

77. Vassos E, Collier DA, Holden S, et al. Penetrance for copy number variants associated with schizophrenia. Hum Mol Genet 2010;19(17):3477-81.

78. Barr WB, Ashtari M, Bilder RM, et al. Brain morphometric comparison of firstepisode schizophrenia and temporal lobe epilepsy. Br J Psychiatry 1997;170: 515-9.

79. Sundram F, Cannon M, Doherty CP, et al. Neuroanatomical correlates of psychosis in temporal lobe epilepsy: voxel-based morphometry study. $\mathrm{Br} \mathrm{J}$ Psychiatry 2010;197(6):482-92.

80. Bryant RA, O'Donnell ML, Creamer M, et al. The psychiatric consequences of traumatic brain injury. Am J Psychiatry 2010;167:312-20.

81. Fleminger S. Head injury. In: David A, Fleminger S, Kopelman MD, et al, editors. Lishman's organic psychiatry: a textbook of neuropsychiatry. 4th edition. Blackwell Publishing; 2009. p. 167-279. 
82. Davidson K, Bagley CR. Schizophrenia-like psychosis associated with organic disorders of the central nervous system: a review of the literature. Current problems of neuropsychiatry. Br J Psychiatry 1969;(Special publication 4):S113-84.

83. David A, Prince M. Psychosis following head injury: a critical review. J Neurol Neurosurg Psychiatry 2005;76(Suppl 1):i53-60.

84. Kim E. Does traumatic brain injury predispose individuals to develop schizophrenia? Curr Opin Psychiatry 2009;21:286-9.

85. Hesdorffer DC, Rauch SL, Tamminga CA. Long-term psychiatric outcomes following traumatic brain injury: a review of the literature. J Head Trauma Rehabil 2009;24:452-9.

86. Malaspina D, Goertz RR, Friedman JH, et al. Traumatic brain injury and schizophrenia in members of schizoiphrenia and bipolar pedigrees. Am J Psychiatry 2001;158:440-6.

87. Nielsen AS, Mortensen PB, O'Callaghan E, et al. Is head injury a risk factor for schizophrenia? Schizophr Res 2002;55:93-8.

88. Fann JR, Burington MS, Leonetti $A$, et al. Psychiatric illness following traumatic brain injury in an adult health maintenance organisation population. Arch Gen Psychiatry 2004;61:53-61.

89. Achte KA, Hillbom E, Aalberg V. Psychoses following war brain injuries. Acta Psychiatr Scand 1969;225:1-94.

90. Dalmau J, Gleichman AJ, Hughes EG, et al. Anti-NMDA receptor encephalitis: case series and analysis of the effects of antibodies. Lancet Neurol 2008;7:1091-8.

91. Barry $\mathrm{H}$, Hardiman $\mathrm{O}$, Healy DG, et al. Anti-NMDA receptor encephalitis: an important differential diagnosis in psychosis. Br J Psychiatry 2011;199:508-9.

92. Baldridge EB, Bessen HA. Phencyclidine. Emerg Med Clin Morth Am 1990;8: 541-50.

93. Gottesman II, Shields J. Schizophrenia: the epigenetic puzzle. Cambridge (United Kingdom): Cambridge University Press; 1982.

94. Dean K, Stevens H, Mortensen PR, et al. Full spectrum of psychiatric outcomes among offspring with parental history of mental disorder. Arch Gen Psychiatry 2010;67:822-9.

95. Ingraham LJ, Kety SS. Adoption studies of schizophrenia. Am J Hum Genet 2000;97:18-22.

96. Cardno AG, Gottesman I. Twin studies of schizophrenia: from bow-and-arrow concordances to Star Wars Mx and functional genomics. Am J Med Genet 2000;97:12-7.

97. Sullivan PF, Kendler KS, Neale MC. Schizophrenia as a complex trait: evidence from a meta-analysis of twin studies. Arch Gen Psychiatry 2003;60:1187-92.

98. Schwartz S, Susser E. Twin studies of heritability. In: Susser E, Schwzrtz S, Morabia A, et al, editors. Psychiatric epidemiology. New York: Oxford University Press; 2006.

99. Kringlen E, Cramer G. Offspring of monozygotic twins discordant for schizophrenia. Arch Gen Psychiatry 1989;46:873-7.

100. Gottesman II, Bertelsen A. Confirming unexpressed genotypes for schizophrenia: risks in the offspring of Fischer's Danish identical and fraternal discordant twins. Arch Gen Psychiatry 1989;46:867-72.

101. Gejman PV, Sanders AR, Kendler KS. Genetics of schizophrenia: new findings and challenges. Annu Rev Genomics Hum Genet 2011;12:121-44.

102. PGC (Schizophrenia Psychiatric Genome-Wide Association Study Consortium). Genome-wide association study identifies five new schizophrenia loci. Nat Genet 2011;43(10):969-76. 
103. ISC (International Schizophrenia Consortium). Common polygenic variation contributes to risk of schizophrenia and bipolar disorder. Nature 2009;460: 748-52.

104. Agerbo E, Mortensen PB, Wiuf C, et al. Modelling the contribution of family history and variation in singly nucleotide polymorphisms to risk of schizophrenia: a Danish national birth cohort-based study. Schizophr Res 2012; 134:246-52.

105. Maher B. Personal genomes: the case of the missing heritability. Nature 2008; 456:18-21.

106. Mitchell KJ, Porteous DJ. Rethinking the genetic architecture of schizophrenia. Psychol Med 2011;41:19-32.

107. O'Tuathaigh CM, Harte M, O'Leary C, et al. Schizophrenia-related endophenotypes in heterozygous neuregulin-1 'knockout' mice. Eur J Neurosci 2010; 31(2):349-58.

108. Ibi D, Nagai T, Koike $H$, et al. Combined effect of neonatal immune activation and mutant DISC1 on phenotypic changes in adulthood. Behav Brain Res 2010;206(1):32-7.

109. Tienari P, Wynne LC, Sorri A, et al. Genotype-environment interaction in schizophrenia-spectrum disorder. Long-term follow-up study of Finnish adoptees. Br J Psychiatry 2004;184:216-22.

110. van Os J, Pedersen CB, Mortensen PB. Confirmation of synergy between urbanicity and familial liability in the causation of psychosis. Am J Psychiatry 2004; 161:2312-4.

111. Mueser KT, McGurk SR. Schizophrenia. Lancet 2004;19:2063-72.

112. Devlin B, Klei L, Myles-Worsely M, et al. Genetic liability to schizophrenia Oceanic Palau: a search in the affected and maternal generation. Hum Genet 2007;121:675-84.

113. Mittal VA, Ellman LM, Cannon TD. Gene-environment interaction and co variation in schizophrenia: the role of obstetric complications. Schizophr Bull 2008; 34:1083-94.

114. Fatemi SH, Folsom TD. The neurodevelopmental hypothesis of schizophrenia, revisited. Schizophr Bull 2009;35:528-48.

115. Schmidt-Kastner R, van Os J, Steinbusch $H$, et al. Gene regulation by hypoxia and the neurodevelopmental origin of schizophrenia. Schizophr Res 2006; 84(2-3):253-71.

116. Nicodemus KK, Marenci S, Batten AJ, et al. Serious obstetric complications interact with hypoxia-regulated vascular expression genes to influence schizophrenia risk. Mol Psychiatry 2008;18:180-4.

117. Clarke MC, Roddy S, Cannon M. Obstetric complications and schizophrenia: Historical overview and new directions. In: Brown AS, Patterson PH, editors. The origins of schizophrenia. New York: Columbia University Press; 2011. p. 96-119.

118. Suvisaari JM, Haukka JK, Tanskanen AJ, et al. Decline in the incidence of schizophrenia in Finnish cohorts born from 1954 to 1965. Arch Gen Psychiatry 1999;56(8):733-40.

119. McGrath JJ, Lawlor DA. The search for modifiable risk factors for schizophrenia. Am J Psychiatry 2011;168(12):1235-8.

120. Yung AR, McGorry PD, McFarlane CA, et al. Monitoring and care of young people at incipient risk of psychosis. Schizophr Bull 1996;22(2):283-303.

121. McGlashan TH, Miller TJ, Woods SW. Pre-onset detection and intervention research in schizophrenia psychoses: current estimates of benefit and risk. Schizophr Bull 2001;27(4):563-70. 
122. Woods SW, Addington J, Cadenhead KS, et al. Validity of the prodromal risk syndrome for first psychosis: findings from the North American Prodrome Longitudinal Study. Schizophr Bull 2009;35(5):894-908.

123. Cannon TD, Cadenhead K, Cornblatt B, et al. Prediction of psychosis in youth at high clinical risk: a multisite longitudinal study in North America. Arch Gen Psychiatry 2008;65(1):28-37.

124. Nelson B, Yung AR. Can clinicians predict psychosis in an ultra high risk group? Aust N Z Psychiatry 2010;44(7):625-30.

125. Ziermans TB, Schothorst PF, Sprong M, et al. Transition and remission in adolescents at ultra-high risk for psychosis. Schizophr Res 2011;126(1-3):58-64.

126. Addington J, Cadenhead KS, Cannon TD, et al. North American Prodrome Longitudinal Study: a collaborative multisite approach to prodromal schizophrenia research. Schizophr Bull 2007;33(3):665-72.

127. Yung AR, Phillips LJ, Yuen HP, et al. Psychosis prediction: 12-month follow up of a high-risk ("prodromal") group. Schizophr Res 2003;60(1):21-32.

128. Gschwandtner U, Pfluger M, Aston J, et al. Fine motor function and neuropsychological deficits in individuals at risk for schizophrenia. Eur Arch Psychiatry Clin Neurosci 2006;256(4):201-6.

129. Pflueger MO, Gschwandtner U, Stieglitz RD, et al. Neuropsychological deficits in individuals with an at risk mental state for psychosis-working memory as a potential trait marker. Schizophr Res 2007;97(1-3):14-24.

130. Eastvold AD, Heaton RK, Cadenhead KS. Neurocognitive deficits in the (putative) prodrome and first episode of psychosis. Schizophr Res 2007;93(1-3):266-77.

131. Kim KR, Park JY, Song DH, et al. Neurocognitive performance in subjects at ultrahigh risk for schizophrenia: a comparison with first-episode schizophrenia. Compr Psychiatry 2011;52(1):33-40.

132. Frommann I, Pukrop R, Brinkmeyer J, et al. Neuropsychological profiles in different at-risk states of psychosis: executive control impairment in the early_and additional memory dysfunction in the late-prodromal state. Schizophr Bull 2011;37(4):861-73.

133. Seidman LJ, Giuliano AJ, Meyer EC, et al. Neuropsychology of the prodrome to psychosis in the NAPLS consortium: relationship to family history and conversion to psychosis. Arch Gen Psychiatry 2010;67(6):578-88.

134. Wood SJ, Pantelis C, Proffitt T, et al. Spatial working memory ability is a marker of risk-for-psychosis. Psychol Med 2003;33(7):1239-47.

135. Smith CW, Park S, Cornblatt B. Spatial working memory deficits in adolescents at clinical high risk for schizophrenia. Schizophr Res 2006;81(2-3):211-5.

136. Hawkins KA, Addington J, Keefe RS, et al. Neuropsychological status of subjects at high risk for a first episode of psychosis. Schizophr Res 2004; 67(2-3):115-22.

137. Carrion RE, Goldberg TE, McLaughlin D, et al. Impact of neurocognition on social and role functioning in individuals at clinical high risk for psychosis. Am J Psychiatry 2011;168(8):806-13.

138. Hambrecht M, Lammertink M, Klosterkotter J, et al. Subjective and objective neuropsychological abnormalities in a psychosis prodrome clinic. Br J Psychiatry Suppl 2002;43:s30-7.

139. Pukrop R, Schultze-Lutter F, Ruhrmann S, et al. Neurocognitive functioning in subjects at risk for a first episode of psychosis compared with first- and multiple-episode schizophrenia. J Clin Exp Neuropsychol 2006;28(8):1388-407.

140. Simon AE, Cattapan-Ludewig K, Zmilacher S, et al. Cognitive functioning in the schizophrenia prodrome. Schizophr Bull 2007;33(3):761-71. 
141. Lencz T, Smith CW, McLaughlin D, et al. Generalized and specific neurocognitive deficits in prodromal schizophrenia. Biol Psychiatry 2006;59(9):863-71.

142. Niendam TA, Bearden CE, Johnson JK, et al. Neurocognitive performance and functional disability in the psychosis prodrome. Schizophr Res 2006;84(1):100-11.

143. Jahshan C, Heaton RK, Golshan S, et al. Course of neurocognitive deficits in the prodrome and first episode of schizophrenia. Neuropsychology 2010;24(1): 109-20.

144. Keefe RS, Perkins DO, Gu H, et al. A longitudinal study of neurocognitive function in individuals at-risk for psychosis. Schizophr Res 2006;88(1-3):26-35.

145. Kelleher I, Murtagh A, Molloy C, et al. Identification and characterization of prodromal risk syndromes in young adolescents in the community: a population-based clinical interview study. Schizophr Bull 2012;38(2):239-46.

146. Kelleher I, Murtagh A, Murphy J, et al. Neurocognition in a community sample of young people at putative ultra high risk for psychosis assessed using the MATRICS consensus neurocognitive battery: processing speed as the core deficit. Cogn Neuropsychiatry, in Press.

147. Dickinson D, Ramsey ME, Gold JM. Overlooking the obvious: a meta-analytic comparison of digit symbol coding tasks and other cognitive measures in schizophrenia. Arch Gen Psychiatry 2007;64(5):532-42.

148. Dickinson D. Digit symbol coding and general cognitive ability in schizophrenia: worth another look? Br J Psychiatry 2008;193(5):354-6.

149. Kelleher I, Connor D, Clarke MC, et al. Prevalence of psychotic symptoms in childhood and adolescence: a systematic review and meta-analysis of population-based studies. Psychol Med 2012. [Epub ahead of print].

150. van Os J, Linscott RJ, Myin-Germeys I, et al. A systematic review and meta-analysis of the psychosis continuum: evidence for a psychosis proneness-persistenceimpairment model of psychotic disorder. Psychol Med 2009;39(2):179-95.

151. Poulton R, Caspi A, Moffitt TE, et al. Children's self-reported psychotic symptoms and adult schizophreniform disorder: a 15-year longitudinal study. Arch Gen Psychiatry 2000;57(11):1053-8.

152. Welham J, Scott J, Williams G, et al. Emotional and behavioural antecedents of young adults who screen positive for non-affective psychosis: a 21-year birth cohort study. Psychol Med 2009;39(4):625-34.

153. Kelleher I, Cannon M. Psychotic-like experiences in the general population: characterizing a high-risk group for psychosis. Psychol Med 2011;41(1):1-6.

154. Polanczyk G, Moffitt TE, Arseneault L, et al. Etiological and clinical features of childhood psychotic symptoms: results from a birth cohort. Arch Gen Psychiatry 2010;67(4):328-38.

155. Laurens KR, Hodgins S, Maughan B, et al. Community screening for psychoticlike experiences and other putative antecedents of schizophrenia in children aged 9-12 years. Schizophr Res 2007;90(1-3):130-46.

156. Blanchard MM, Jacobson S, Clarke MC, et al. Language, motor and speed of processing deficits in adolescents with subclinical psychotic symptoms. Schizophr Res 2010;123(1):71-6.

157. Cannon M, Moffitt TE, Caspi A, et al. Neuropsychological performance at the age of 13 years and adult schizophreniform disorder: prospective birth cohort study. Br J Psychiatry 2006;189:463-4.

158. Kelleher I, Clarke MC, Rawdon C, et al. Neurocognition in the extended psychosis phenotype: performance of a community sample of adolescents with psychotic symptoms on the MATRICS neurocognitive battery. Schizophr Bull, in press. 
159. Lencz T, Lambert C, DeRosse P, et al. Runs of homozygosity reveal highly penetrant recessive loci in schizophrenia. Proc Natl Acad Sci 2007;104(50):19942-7.

160. Sullivan PF, Lin D, Tzeng JY, et al. Genomewide association for schizophrenia in the CATIE study: results of stage 1. Mol Psychiatry 2008;13(6):570-84.

161. O'Donovan MC, Craddock N, Norton N, et al. Identification of loci associated with schizophrenia by genome-wide association and follow-up. Nat Genet 2008;40(9): 1053-5.

162. Need AC, Goldstein DB. Whole genome association studies in complex diseases: where do we stand? Dialogues Clin Neurosci 2010;12(1):37-46.

163. Purcell SM, Wray NR, Stone JL, et al. Common polygenic variation contributes to risk of schizophrenia and bipolar disorder. Nature 2009;460(7256):748-52.

164. Stefansson H, Ophoff RA, Steinberg S, et al. Common variants conferring risk of schizophrenia. Nature 2009;460(7256):744-7.

165. Shi J, Levinson DF, Duan J. Common variants on chromosome 6p22.1 are associated with schizophrenia. Nature 2009;460(7256):753-7.

166. Ikeda M, Aleksic B, Kirov G, et al. Copy number variation in schizophrenia in the Japanese population. Biol Psychiatry 2010;67(3):283-6.

167. Yue WH, Wang HF, Sun LD, et al. Genome-wide association study identifies a susceptibility locus for schizophrenia in Han Chinese at 11p11.2. Nat Genet 2011;43(12):1228-31.

168. Shi $Y, L i Z, X u Q$, et al. Common variants on $8 p 12$ and $1 q 24.2$ confer risk of schizophrenia. Nat Genet 2011;43(12):1224-7. 